\title{
Non-Compressive Disorders of the Chiasm
}

\author{
Valerie A. Purvin • Aki Kawasaki
}

Published online: 2 May 2014

(C) Springer Science+Business Media New York 2014

\begin{abstract}
Chiasmal dysfunction produces a characteristic clinical picture, regardless of the mechanism. In most cases a compressive lesion is the cause. In occasional cases, however, no such extrinsic mass is found and other possible etiologies must be explored. In some of these cases, the pathologic process is identifiable with appropriate neuroimaging. For example, inflammation, infiltrative tumors, and radiation necrosis produce intrinsic chiasmal enhancement. Chiasmal ischemia may require specialized magnetic resonance (MR) sequences for diagnosis. Chiasmal hemorrhage, trauma and chiasmal herniation typically produce distinctive changes on noncontrasted imaging. In cases of metabolic insult, either toxic or hereditary, radiographic changes are typically absent. In each of these, the correct diagnosis can usually be made with a combination of clinical and radiographic features.
\end{abstract}

Keywords Optic chiasm · Chiasm - Optic nerve · Chiasmitis · Bitemporal visual field defect · Demyelination · Chiasmal

This article is part of the Topical Collection on Neuro-Ophthalmology

V. A. Purvin

Department of Ophthalmology, Indiana University Medical Center, Indianapolis, IN, USA

\section{A. Purvin}

Glick Eye Institute and Ophthalmology Center, 1160 West Michigan Street, Indianapolis, IN 46202, USA

\section{A. Kawasaki}

Department of Ophthalmology, University of Lausanne, Lausanne, Switzerland

\section{A. Kawasaki $(\bowtie)$}

Hôpital Ophtalmique Jules Gonin, Avenue de France 15, Lausanne, Switzerland 1004

e-mail: aki.kawasaki@fa2.ch glioma $\cdot$ Chiasmal trauma $\cdot$ Ethambutol toxicity $\cdot$ Radiation optic neuropathy

\section{Introduction}

A chiasmal lesion is suspected when bilateral temporal visual field loss, partial or complete, is observed. Patients are often asymptomatic or have nonspecific visual difficulties until central visual dysfunction occurs. When bitemporal loss is complete, odd visual phenomena may occur. "Hemifield slide" occurs when the remaining nasal hemifields fail to maintain alignment along the vertical meridian, slipping apart vertically or horizontally $[1,2]$. This occurs because of insufficient corresponding retinal points needed to maintain fusion. Patients with hemifield slide complain of intermittent diplopia, poor depth perception, and gaps in straight lines. Despite this lack of overlapping fields, prismatic and/or surgical correction of a manifest strabismus can improve fusional capacity and reduce symptoms in such patients $[1,2]$.

Another interesting phenomenon secondary to bitemporal hemianopsia is "post-fixational blindness". This is a disturbance of depth perception, particularly bothersome during near work. When fixating a target, the area distal to the target is viewed only with overlapping temporal hemifields which, in this case, are nonseeing. Thus, the patient is blind for all objects beyond the point of fixation. The area in front of the target is viewed within the intact nasal hemifields, permitting binocular vision. Patients with postfixational blindness complain that objects appear and disappear as they change their point of fixation [3].

The large majority of lesions causing chiasmal visual loss are extrinsic masses which compress the chiasm, most commonly pituitary adenoma, suprasellar meningioma, or craniopharyngioma. Yet, there are important causes of chiasmal visual loss that are not due to an extrinsic mass and 
these intrinsic or otherwise noncompressive lesions form the basis of this review.

\section{Chiasmal Inflammation}

As in optic neuritis, inflammation of the optic chiasm is most often a demyelinating disorder [4] (Fig. 1a). Occasional cases are due to a specific infectious/inflammatory systemic disorder or occur shortly after a viral illness or immunization [5]. Specific causes of chiasmal inflammation include Epstein Barr virus, mumps, Lyme disease, systemic lupus erythematosus, varicella zoster, sarcoidosis, and Langherhans histiocytosis [6-12].

Demyelinating chiasmal neuritis occurs as an isolated idiopathic event [4] or as part of relapsing-remitting multiple sclerosis (MS), acute demyelinating encephalomyelitis or neuromyelitis optica $[13,14]$. Demographic features of idiopathic demyelinating chiasmal neuritis resemble those of optic neuritis, showing a strong female predilection [4]. Most cases occur in adults but idiopathic chiasmal optic neuritis has been reported in patients as young as 4 years of age [15•]. In contrast to optic neuritis, pain is infrequent, reported by only $20 \%$ of patients in 1 large series (vs $90 \%$ of patients with optic neuritis) [4]. Positive visual phenomena were reported by $25 \%$ of patients, often accompanied by light sensitivity. The temporal course of chiasmal neuritis is also similar to that of optic neuritis, vision worsening for days to weeks then stabilizing with eventual substantial improvement. In the largest series, consisting of 20 patients with idiopathic chiasmal neuritis reported by Kawasaki and Purvin, $97 \%$ of patients had final visual acuity of 20/40 or better [4]. However, $40 \%$ developed clinically definite MS from 3 months to 3 years after onset of visual loss, usually within the first year.

In addition to intrinsic inflammation as described above, the chiasm is sometimes affected by an adjacent inflammatory process. For example, inflammation of the meninges may involve the chiasm, with etiologies including tuberculosis $[16,17]$, rheumatoid pachymeningitis [18], Wegener's granulomatosis [19], and syphilis. Lymphocytic hypophysitis is due to an autoimmune attack on the pituitary gland and stalk, most commonly occurring during pregnancy. In this form of perichiasmal inflammation visual loss can be due to spread of the inflammatory process to involve the chiasm or compression by the inflamed pituitary stalk [20].

\section{Vascular}

Recent advances in neuroimaging have increased our ability to detect and define ischemia of the anterior visual pathways [21]. Specifically, the addition of diffusion weighted imaging (DWI) and diffusion tensor imaging (DTI) $[22,23]$ are particularly valuable in this setting. DTI, which uses multiple diffusion directions of analysis and has a higher signal to noise ratio, is especially sensitive.

Despite this increased sensitivity, infarction of the optic chiasm is an uncommon diagnosis. Because of its complex and redundant vascular supply, the chiasm is relatively resistant to ischemia. Two cases of embolic chiasmal infarction have been described, 1 following open heart surgery [23] and the other because of atrial fibrillation [24•]. In addition, an iatrogenic case because of embolism occurred during treatment of an ophthalmic segment aneurysm in which there was occlusion of the superior hypophyseal artery [25].

In addition to infarction, vascular damage to the optic chiasm can be caused by hemorrhage, either from an extrinsic mass, typically a pituitary tumor (termed pituitary apoplexy) or from an intrinsic lesion, most often a cavernous malformation (termed chiasmal apoplexy) (Fig. 1c). Patients with chiasmal apoplexy typically present with acute bilateral visual loss and headache. In a large series of patients with cavernous malformations (CM) involving the optic pathways, there was evidence of old or chronic bleeding in $15 \%$ [26]. Most patients are treated with surgical resection, often with good visual outcome. Rarely, hemorrhage within the chiasm is caused by an intrinsic tumor such as glioma [27].

\section{Neoplasm}

Optic pathway glioma is usually a disease of childhood. The majority of cases are sporadic but the association of this tumor with neurofibromatosis type 1 is clear. Extension to involve the chiasm occurs in $40 \%-70 \%$ of cases, more commonly in the sporadic form (Fig. 2a and b). Patients with chiasmal glioma usually have slowly progressive bitemporal visual loss, occasionally associated with hormonal disturbance and/ or hydrocephalus due to exophytic extension. Such extension is more common in sporadic case [28, 29]. Optic pathway glioma in childhood most often follows a benign course, prompting debate regarding pathologic classification as tumor vs hamartoma.

In contrast to its limited growth potential in childhood, optic pathway glioma in older adults has an aggressive course, consistent with its pathologic features of high grade malignancy. These patients present with acute onset of visual loss that may be mistaken for optic neuritis or ischemic optic neuropathy [30-32]. Tumors that are initially confined to 1 intra-orbital optic nerve typically show subsequent progression to the chiasm and then tracts; in occasional cases the chiasm is the initial site of the tumor [31] (Fig. 2c and d). The typical course includes rapid progression leading to blindness within weeks and death within months. Optic nerve and chiasmal infiltration can also occur in multifocal glioma, termed gliomatosis cerebri [33]. Such anterior visual pathway 
Fig. 1 Examples of noncompressive chiasmal lesions. a, Chiasmal optic neuritis in a 32year-old woman with acute bilateral visual blur. Visual acuity was 20/20 in each eye but dyschromatopsia and a bitemporal visual field defect were found. Post-contrast T1weighted coronal MRI shows mild enlargement and enhancement of the right side of the chiasm. b, Chiasmal herniation following resection of a large pituitary adenoma. Coronal MRI shows a thin, distended chiasm sagging into the greatly enlarged and «empty» sella. c, Chiasmal apoplexy in a 35-year-old woman with abrupt onset of visual loss in the right eye and a mild temporal defect in the left eye. This noncontrasted axial CT shows hyperintensity in the right side of the chiasm consistent with hemorrhage. d, Primary CNS lymphoma in a 42-year-old man with AIDS. Axial T1weighted MRI with gadolinium shows enlargement of the chiasm with a ring enhancement pattern
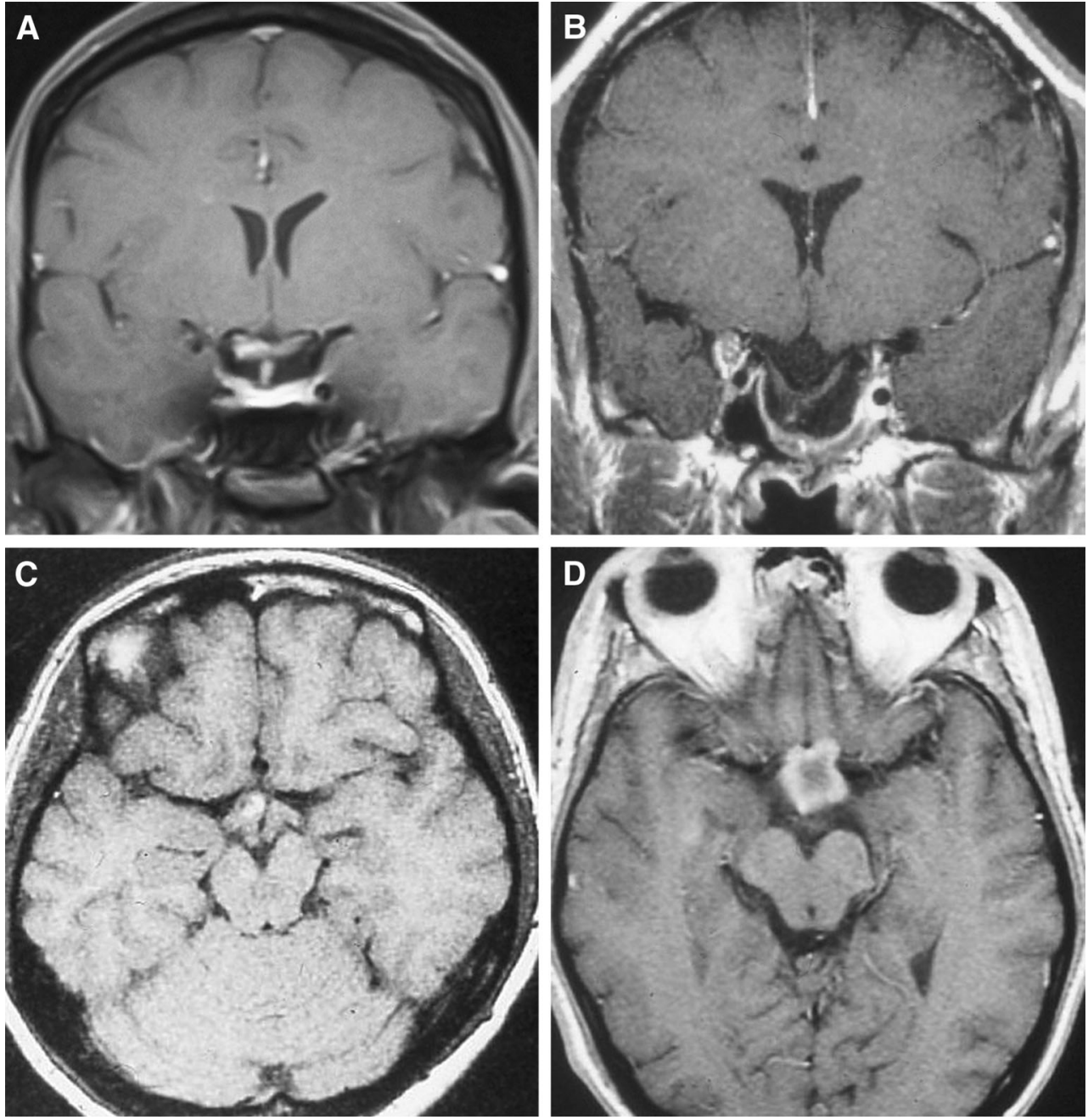

involvement occurs in approximately $10 \%$ of cases and may be mistaken for multiple sclerosis [34].

Management of optic nerve glioma in children and young adults has been controversial, largely because of its variable growth potential. Initial observation is the preferred strategy, embarking on treatment in response to clinical worsening, not necessarily on radiographic growth alone. Listernick simplified the definition of ophthalmologic progression to be either: a 2-line change in Snellen, HOTV or Lea visual acuity or a 2octave decline in Teller acuity [35].

The extent of posterior extension is sometimes used to direct treatment. Specifically, resection of an involved intracranial optic nerve is sometimes undertaken if the tumor is progressing and is thought to terminate anterior to the optic chiasm. MRI is the standard noninvasive method for making this determination. However, a recent study of 13 such patients who were studied with MRI and subsequently underwent surgery found that in 5 patients tumor extended into the chiasm despite an MRI appearance suggesting the contrary [36 $]$. Diffusion tensor tractography has also been used to obtain more detailed information about the relationship of visual fibers to tumor in patients with optic pathway gliomas of childhood [37].

Rarely, chiasmal infiltration is due to metastatic tumor. Isolated infiltration of the optic chiasm by a primary central nervous system large B-cell lymphoma most often occurs in the setting of immunosuppression [38] (Fig. 1d). In a subset of patients, diagnosis can be made based on CSF cytopathology, flow cytometry and immuno-phenotyping (mainly for pan-B cell markers) but in many cases diagnosis is only possible with biopsy [39, 40]. Primary intra-chiasmal germinoma [41] and posterior extension of retinoblastoma [42] have also been reported.

\section{Toxic Damage to Chiasm}

The potential toxic effect of ethambutol on the optic nerve is well-known and this dose dependent adverse effect may sometimes extend to the chiasm. The incidence of optic neuropathy is reportedly $<1 \%$ at doses of $15 \mathrm{mg} / \mathrm{kg} / \mathrm{day}$, and as high as $18 \%-50 \%$ at $>35 \mathrm{mg} / \mathrm{kg} /$ day $[43,44]$. Conditions 
Fig. 2 Examples of chiasmal glioma. a and $\mathbf{b}$, Benign chiasmal glioma in a 15-year-old boy with NF1 and very mild chiasmal visual loss. Axial and coronal T1weighted MR scans show diffuse enlargement of the chiasm without enhancement on postcontrast sequences. $\mathbf{c}$ and $\mathbf{d}$, Malignant glioma of the anterior visual pathway in a 53-year-old woman who presented with acute right optic neuropathy initially diagnosed as optic neuritis. Over the next 2 months, her tumor progressed to involve the entire pregeniculate visual system and eventually the brainstem. T1weighted axial and coronal MRI with gadolinium shows enhancement and enlargement of the prechiasmal optic nerves, the chiasm and left optic tract
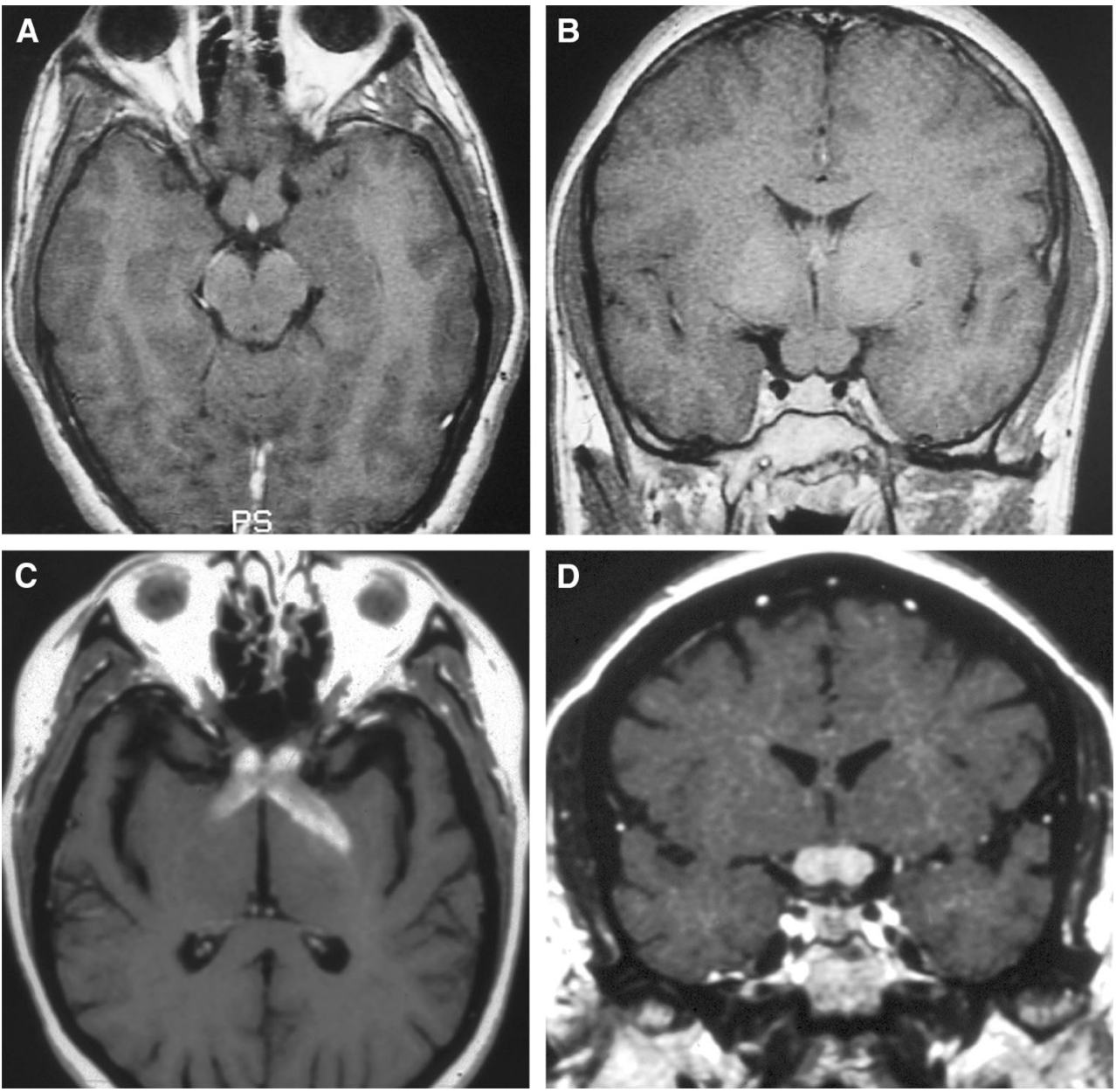

that increase the risk for ethambutol toxicity include renal or hepatic insufficiency, older age, diabetes, chronic alcohol, or tobacco use, and the concomitant use of isoniazid. The mechanism of damage is not fully understood but evidence of copper chelation, zinc accumulation in lysosomes and decreased cytosolic calcium suggest compromised mitochondrial function in retinal ganglion cells. Kinoshita et al examined retinal function and morphology in monkeys with ethambutol toxicity the first paper to describe ethambutol-induced lesions in the retina [45•]. The authors found severe necrosis of the retinal ganglion cells in the parafoveal region with a preferential loss on the nasal side. Outer retinal photoreceptor structure and function were preserved. This is consistent with a preferential vulnerability of the papillomacular bundle to ethambutol. Demyelination and glial reaction were noted in the optic nerves, chiasm, and optic tracts [45•].

Optic nerve and/or chiasmal dysfunction typically occur 2 to 5 months after drug initiation though occasional patients experience visual loss much earlier, within weeks or even days of starting treatment. While central or cecocentral scotomas are the classic visual field defect, ethambutol toxicity can produce a bitemporal hemianopia. MRI imaging may reveal abnormal signal changes within the body of the chiasm [46, 47].

Patients should be asked about visual symptoms at each medical visit and monthly ophthalmic examination is recommended for patients taking $>15 \mathrm{mg} / \mathrm{kg} /$ day or those at higher risk of toxicity. Many patients recover some or all visual function after stopping the drug but in others visual loss persists and may even continue to worsen. There are no predictive factors to identify those in whom vision will or will not recover.

\section{Radiation Damage}

Radiation therapy for intracranial or sinus tumors sometimes damages neighboring structures, including the optic nerve and chiasm. The site of damage in these cases is most likely the vascular endothelium. Patients present with sudden, painless bilateral sequential or simultaneous visual loss that occurs within 3 years (peak incidence at 12-18 months) following radiation therapy [48]. Visual loss is rapidly progressive and severe with more than $85 \%$ of patients having final acuity of 
20/200 (0.1) or worse. Visual field defects often have a temporal component, indicating chiasmal involvement. MRI shows enlargement and postcontrast enhancement of the optic nerves, chiasm, and/or tract.

There is no known effective treatment for radiationinduced optic neuropathy or chiasmopathy. Anecdotal success has been reported with hyperbaric oxygen, particularly when given at higher atmospheres within 72 hours of visual loss [49•]. Other measures such as anticoagulation and corticosteroids are commonly used due to their availability in the urgent situation, but efficacy has not been proven. Pentoxifylline has been found to be beneficial in some cases of cerebral radionecrosis and has, therefore, been tried in radiation optic neuropathy [50]. Farooq et al described a 24-year-old woman who lost vision in both eyes over a 2 -week period despite intravenous methylprednisolone [51]. Five years earlier, she had undergone radiation therapy for tectal tumor. Visual acuity was no light perception in the right eye and 20/100 in the left eye. Her treatment was changed to a combination of intravenous bevacizumab plus dexamethasone plus pentoxifylline and within 2 weeks, vision improved to $20 / 50$ and 20/100 with a partial bitemporal hemianopia. She eventually recovered to $20 / 20$ and $20 / 25$ [51]. A similar clinical recovery was reported by Chahal et al in a patient given a brief course of dexamethasone and long-term therapy with pentoxifylline and vitamin E. These 2 reports suggest a potential beneficial effect which is perhaps synergistic between pentoxifylline and the antivascular endothelial growth factor bevacizumab. Patients with radiation retinopathy have shown structural and functional improvement following intravitreal bevacizumab (Avastin) injection [52]. This benefit, unfortunately, is not sustained, requiring repeat treatment.

\section{Chiasmal Trauma}

Situated in a protective niche at the base of the brain, the chiasm is rarely damaged by trauma. The chiasm is suspended in the suprasellar cistern about $10 \mathrm{~mm}$ above the pituitary gland which rests in the sella turcica of the sphenoid bone. Posteriorly, the chiasm borders the anterior inferior wall of the third ventricle and is flanked by the supraclinoid segments of the carotid arteries and inferolaterally by the cavernous sinuses. The magnitude of head injury associated with chiasmal trauma is typically severe, resulting in significant damage to other structures such as the craniofacial bones, hypothalamicpituitary axis, clivus, neighboring cranial nerves, and carotid arteries.

The largest series of patients with chiasmal trauma evaluated at a single institution was reported by Hassan et al and consisted of 19 patients seen over a 30-year period [53]. The typical profile was that of a young male (average age 25 years, range 4-41 years) who had a motor vehicle accident, accounting for $58 \%$ of cases. Other causes of injury were falls $(21 \%)$, cycling (11\%), horseback riding (5\%), and assault (5\%). Two-thirds of patients sustained a skull fracture, most commonly a combined frontal and basilar skull fracture (31\%) or severe frontal bone fracture $(21 \%)$.

There are several possible mechanisms to account for chiasmal damage secondary to head trauma [54]. One theory is mechanical disruption of chiasmal fibers. Heinz et al described 2 patients with bitemporal visual field loss following blunt frontal head trauma [55]. Both patients had a midline basilar skull fracture traversing the midclivus and continuing through the sella turcica, dorsum sella, and sphenoid bone. Such a fracture suggests a sudden and violent shifting along the longitudinal axis of the skull base at the moment of impact, presumably sufficient to shear the body of the chiasm [55]. Segal et al published a radiographic and histopathologic demonstration of complete chiasmal transection following head trauma [56]. Other proposed mechanisms include contusion with intrachiasmal hemorrhage (microscopic or gross), vascular compromise with secondary chiasmal ischemia, or compression by herniating gyrus rectus of the frontal lobe $[54,56]$.

The clinical presentation consists of severe visual loss following head trauma. In the Hassan series, 10 of 19 (53\%) patients had no light perception in 1 eye combined with a temporal hemianopia in the fellow eye [53]. None of these patients experienced any recovery in the blind eye. Nine patients had a bitemporal hemianopia which was typically complete. Seventy-five percent of patients retained 20/40 (0.5) acuity in 1 eye. In a series of 10 patients reported by Atipo et al 3 patients had relatively minor head trauma without associated craniofacial fractures [57]. The visual loss in these 3 patients was delayed by $0.5-11$ days and visual function (acuity and bitemporal defect) recovered in 1 patient. There is no known treatment for traumatic chiasmal syndrome and management usually focuses on other associated aspects of trauma. Treatment with high dose corticosteroids is sometimes used but there is no evidence demonstrating efficacy.

Due to its protected position, trauma sufficient to damage the chiasm usually causes other deficits. These include diabetes insipidus and/or pituitary dysfunction in about one-third of patients and cranial neuropathy in over half of patients (oculomotor nerve palsy in $53 \%$, abducens nerve palsy $47 \%$, trochlear nerve palsy $21 \%$, and anosmia $21 \%$ ). Two patients in the series of Hassan et al also had deficits of cranial nerve $\mathrm{V}$, VII, and VIII [53].

An unusual form of chiasmal trauma in a patient undergoing treatment for a retinal detachment has been recently reported [58]. In this rare operative complication, C3F8 perfluoropropane gas from the vitreous cavity migrated into the optic nerve and posteriorly to the chiasm, causing visual loss. This sequence of events is presumed due to markedly elevated intra-ocular pressure. 


\section{Chiasmal Herniation}

The chiasm lies in the suprasellar cistern separated from the sella turcica and pituitary gland by the diaphragma sella. When the diaphragma sella is defective, for example, after pituitary surgery, the suprasellar arachnoid space and its contents including the chiasm can herniate into the sella turcica [59] (Fig. 1b). The tethering effect of the downwardly displaced chiasm may cause visual loss [60]. However, the degree of herniation does not predict the severity of visual loss.

Delayed visual loss following dopamine agonist treatment (bromocriptine, pergolide, cabergoline, and quinagolide) of prolactinomas has been reported in association with chiasmal hernation secondary to rapid shrinkage of tumor [61-63]. The response of prolactinomas to medical therapy is very favorable with normalization of serum prolactin levels in $70 \%-100 \%$ of patients and a significant decrease in tumor size in $80 \%-90 \%$ [64]. This rapid involution of the tumor may result in chiasmal prolapse, a diagnosis which is confirmed with MRI.

Jones et al described 7 patients with chiasmal herniation following successful dopamine agonist treatment of a macroprolactimona [61]. Before treatment, all patients had visual loss and very high prolactin levels (median $86,000 \mathrm{mU} / \mathrm{l})$. Following treatment, all patients demonstrated adequate suppression of serum prolactin and radiographicallydetectable tumor reduction and visual recovery. Within a median time of 10 months (range 4-120 months), all patients developed recurrent visual loss without evidence of tumor recurrence. In each case, chiasmal herniation was identified as the most likely cause of recurrent visual loss. Reduction or withdrawal of treatment led to stabilization and/or resolution of visual loss in all patients. The mechanism in such cases, however, remains controversial. For example, Chuman et al have noted that visual recovery typically occurs without a corresponding change in the position of the chiasm. They have, therefore, proposed that drug toxicity or ischemia due to vasospasm, rather than mechanical traction, may be a more plausible mechanism [63]. They recommend that symptomatic chiasmal herniation following dopaminergic therapy be treated by decreasing drug dosage rather than with surgical intervention.

Surgical intervention in such cases attempts to lift the chiasm out of the sella (chiasmopexy) and has been reported to be a viable option for treating symptomatic chiasmal hernation, particularly in patients who had undergone surgery for their primary tumor. Various approaches including the transcranial, transsphenoidal, or transglabellar approach, have been described and the intervention may include fibrinolysis of local adhesions, and/or filling of the empty sella with material such as fat, bone, or coils to return the chiasm to a more normal position [65-67].

\section{Hereditary Optic Neuropathy}

Leber hereditary optic neuropathy (LHON) is a maternally inherited mitochondrial disorder affecting the optic nerves in which the typical clinical presentation is subacute, painless, sequential visual loss in young adult males [68]. Neuroimaging of the pregeniculate visual pathway is usually normal in patients with LHON but occasionally MRI abnormalities appear, usually weeks to months after the onset of visual loss. Within weeks of visual loss, there may be enlargement of the retrobulbar or intracranial optic nerves and/or chiasm $[69,70]$. If there is also contrast enhancement of the affected structure, the clinical picture may be mistaken for demyelinating optic neuritis or chiasmal neuritis.

In other patients, MRI shows high T2 signal in normalsized or moderately enlarged prechiasmal optic nerves, chiasm and even optic tracts [71•]. Similar increased signal also can also be seen on short time inversion recovery sequences (STIR). These MRI changes appear in the subacute clinical phase, usually several months after visual loss, and may persist for several months. Batoglu et al published a photo essay of a patient with the 11778 mutation for LHON and sequential visual loss [72]. The MRI T2-hyperintensity first appeared in the right side of the chiasm 3 months after visual loss in the right eye and 6 months later developed to bilateral hyperintense signal within the body of the chiasm. No enlargement or contrast enhancement of the optic nerves or chiasm was noted. It has been proposed that the increased T2 signal represents local edema and demyelination in the subacute phase followed by gliosis in the chronic phase of disease $[71 \cdot, 72]$.

Occasionally, other forms of hereditary optic neuropathy may also produce chiasmal clinical features, though not confirmed with radiographic findings. We have seen 2 patients with Wolfram's syndrome (diabetes mellitus, diabetes insipidus, deafness, and optic atrophy) whose progressive visual loss took the form of bitemporal hemianopic defects.

\section{Conclusions}

The optic chiasm is subject to compression by extrinsic mass lesions involving surrounding structures. However, a variety of other (noncompressive) processes can also involve the chiasm. In such cases, the clinical features usually point to the correct localization of the disease process but advances in neuroimaging have enabled us to confirm the suspected site and often provide additional diagnostic information.

MRI has been extremely useful for identifying inflammation and neoplasia of the chiasm. However, though MRI images are highly sensitive, they are not particularly specific. Thus, inflammation, demyelination, and tumor are accompanied by similar radiological changes, typically consisting of 
enlargement and/or enhancement of the body of the chiasm. Radiation necrosis also produces similar changes on MRI. We therefore routinely use clinical information along with the radiologic findings to arrive at a diagnosis and to help guide treatment. Chiasmal ischemia and infarction are uncommon and require more specialized radiographic techniques. Chiasmal hemorrhage is readily seen on noncontrast CT images.

In addition, recent reports have demonstrated that mitochondrial-related optic neuropathies (specifically, Leber hereditary optic neuropathy and ethambutol toxicity) may also induce signal changes within the body of the chiasm. In some of these cases of metabolic dysfunction, the radiographic findings are accompanied by clinical features of chiasmal dysfunction.

Our clinical judgment is based in part on the likelihood of a particular condition. When the clinical findings indicate a chiasmal syndrome, we proceed with neuroimaging, anticipating that we will find a benign skull base tumor. We sometimes share this educated guess with patients so that they will be partly prepared for receiving the diagnosis. When the scan fails to reveal the expected compressive mass, we should have a fallback plan: what else could produce these signs and symptoms? We hope that the information reviewed in this paper helps the physician in this clinical scenario.

\section{Compliance with Ethics Guidelines}

Conflict of Interest Valerie A. Purvin has received book royalties from Cambridge University Press. Aki Kawasaki has received a research grant from Egalité; University of Lausanne, honoraria from Springer for editorial service, and book royalties from Cambridge University Press.

Human and Animal Rights and Informed Consent This article does not contain any studies with human or animal subjects performed by any of the authors.

\section{References}

Papers of particular interest, published recently, have been highlighted as:

- Of importance

1. Pula JH, Fischer M, Kattah JC. Hemifield slide from traumatic optic chiasmopathy. J Clin Neurosci. 2014. doi:10.1016/j.jocn.2014.01. 001.

2. Van Waveren M, Jägle $H$, Besch D. Management of strabismus with hemianopic visual field defects. Graefes Arch Clin Exp Ophthalmol. 2013;251:575-84.

3. Weber KP, Landau K. Mind the gap! Postfixational blindness due to traumatic rupture of the optic chiasm. Neurology. 2013;80:e197-8.

4. Kawasaki A, Purvin VA. Idiopathic chiasmal neuritis: clinical features and prognosis. Arch Ophthalmol. 2009;127:76-81.
5. Lee S-Y, Wang A-G, Yen M-Y. Chiasmal optic neuritis: a report of 3 cases. Taiwan J Ophthalmol. 2012;2:68-72.

6. Purvin V, Herr GJ, DeMyer W. Chiasmal neuritis as a complication of Epstein-Barr virus infection. Arch Neurol. 1988;45:458-60.

7. Scott IU, Silva-Lepe A, Siatkowski RM. Chiasmal optic neuritis in Lyme disease. Am J Ophthalmol. 1997;123:136-8.

8. Irioka T, Akaza M, Nakao K, et al. Chiasmal optic neuritis following mumps parotitis. J Neurol. 2008;255:773-4.

9. Frohman LP, Frieman BJ, Wolansky L. Reversible blindness resulting from optic chiasmitis secondary to systemic lupus erythematosus. J Neuroophthalmol. 2001;21:18-21.

10. Greven CM, Singh T, Stanton CA, et al. Optic chiasm, optic nerve, and retinal involvement secondary to varicella-zoster virus. Arch Ophthalmol. 2001;21:18-21.

11. Tang RA, Grotta JC, Lee KF, et al. Chiasmal syndrome in sarcoidosis. Arch Ophthalmol. 1983;101:1069-73.

12. Hervey-Jumper SL, Ghori A, Ziewacz JE, et al. Langerhans cell histiocytosis of the optic chiasm: case report. Neurosurgery. 2011;68:E556-61.

13. DiMario Jr FJ, Hajjar M, Ciesielski T. A 16-year-old girl with bilateral visual loss and left hemiparesis following immunization against Human Papilloma Virus. J Child Neurol. 2010;25:773-4.

14. Costa RM, Santos AC, Costa S. An unusual chiasmal visual defect in a patient with neuromyelitis optica: case report. Arq Bras Oftalmol. 2007;70:153-5.

15. Calawaerts E, De Waele L, Buyse G, et al. Chiasmal optic neuritis in a 4-year-old girl. Bull Soc Belge Ophthalmol. 2012;320:5-10. While chiasmal optic neuritis typically affects young adults, children are occasionally affected, as evidenced by this report.

16. Garg RK, Paliwal V, Malhotra HS. Tuberculous optochiasmatic arachnoiditis: a devastating form of tuberculous meningitis. Expert Rev Antiinfective Ther. 2011;9:719-29.

17. Joseph M, Mendonca TM, Vasu U, et al. Paradoxical growth of presumed optochiasmatic tuberculomas following medical therapy. JAMA Ophthalmol. 2013;131:1463-7.

18. Weinstein GW, Powell SR, Thrush WP. Chiasmal neuropathy secondary to rheumatoid pachymeningitis. Am J Ophthalmol. 1987;104:439-40.

19. Hughes J, Barkhoudarian G, Ciarlini P, et al. Refractory pituitary granulomatosis with polyangiitis (Wegener's) treated with rituximab. Endocr Pract. 2013;19:e1-7.

20. Leung GKK, Lopes M-B S, Thorner MO, et al. Primary hypophysitis: a single-center experience in 16 cases. J Neurosurg. 2011;15:262-71.

21. Quigley EP, Osborn A. Advanced imaging of anterior visual pathway ischemia: state of the art and future directions. J Neuroophthalmol. 2010;30:213-5.

22. Oku H, Matsuo J, Etomi T, et al. Acute infarction at the optochiasmal junction detected by diffusion weighted magnetic resonance imaging. J Neuroophthalmol. 2009;33:257-60.

23. Fabian ID, Greenberg G, Huna-Baron R. Chiasmal stroke following open-heart surgery. J Neuroophthalmol. 2010;30:219-21.

24. Shelton JB, Digre KB, Katz BJ, et al. Chiasmal stroke in patient with atrial fibrillation and complete occlusion of right internal carotid artery. J Neuroophthalmol. 2012;32:189. This report documents clinical and imaging findings in this rare case of embolic stroke involving the chiasm.

25. Johnson JN, Elhammady M, Post J, et al. Optic pathway infarct after Onyx HD aneurysm embolization: visual pathway ischemia from superior hypophyseal artery occlusion. BMJ Case Rep. 2013. doi:10.1136/bcr-2013-010968.

26. Liu JK, Lu Y, Raslan AM, et al. Cavernous malformation of the optic pathway and hypothalamus: analysis of 65 cases in the literature. Neurosurg Focus. 2010;29:E17.

27. Ball BG, Wetmore C, Giannini C, et al. Opticochiasmatic apoplexy in a five-year-old. Pediatr Neurosurg. 2011;47:279-83. 
28. Avery RA, Fisher MJ, Liu GT. Optic pathway gliomas. J Neuroophthalmol. 2011;31:269-78.

29. Shapey J, Danesh-Meyer HV, Kaye AH. Diagnosis and management of optic nerve glioma. J Clin Neurosci. 2011;18: 1585-91.

30. Matloob S, Fan JC, Danesh-Meyer HV. Multifocal malignant optic glioma of adulthood presenting as an acute anterior optic neuropathy. J Clin Neurosci. 2011;18:974-7.

31. Dinh TT, Wang YY, Rosenfeld JV, et al. Glioblastoma of the optic chiasm. J Clin Neurosci. 2007;14:502-5.

32. Liu Y, Zhang-Nunes S, Zhu X, et al. Late adult onset optic pathway astrocytoma. J Clin Neurosci. 2013;20:1610-2.

33. Traynis I, Singer S, Winterkorn J, et al. Infiltration of the optic chiasm, nerve, and disc by gliomatosis cerebri. J Neuroophthalmol. 2014;34:44-6.

34. Peretti-Viton $\mathrm{P}$, Brunel $\mathrm{H}$, Chinot $\mathrm{O}$, et al. Histological and MR correlations in gliomatosis cerebri. J Neurooncol. 2002;59:249-59.

35. Listernick R, Ferner RE, Liu GT, et al. Optic pathway gliomas in neurofibromatosis-1: controversies and recommendations. Ann Neurol. 2007;61:189-98.

36. Spicer GJ, Kazim M, Glass LRD, et al. Accuracy of MRI in defining tumor-free margin in optic nerve glioma surgery. Ophthal Plast Reconstr Surg. 2013;29:277-80. Expanding on previous anecdotal reports, this study quantifies the accuracy of MRI for predicting posterior extension of optic nerve glioma.

37. Lober RM, Guzman R, Chesier SH, et al. Application of diffusion tensor tractography in pediatric optic pathway glioma. J Neurosurg. 2012;10:273-80.

38. Tsutsumi K, Horiuchi T, Aoyama T, et al. Isolated primary malignant lymphoma arising from the optic chiasm. J Clin Neurosci. 2013;20:1783-6.

39. Baraniskin A, Deckert M, Schulte-Altedorneburg, et al. Current strategies in the diagnosis of diffuse large B-cell lymphoma of the central nervous system. Br J Haematol. 2012. doi:10.1111/j.13652141.2011

40. Zelefsky JR, Revercomb CH, Lantos G, et al. Isolated lymphoma of the anterior visual pathway by optic nerve biopsy. J Neuroophthalmol. 2008;28:36-40.

41. Xia C, Liu Z, Zhang R, et al. Primary intrinsic optic chiasm germinoma. J Clin Neurosci. 2011;18:860-2.

42. Mataftsi A, Zografos L, Balmer A, et al. Chiasmatic infiltration secondary to late malignant transformation of retinoma. Ophthalmic Genet. 2012;33:155-8.

43. Menon V, Jain D, Saxena R, et al. Prospective evaluation of visual function for early detection of ethambutol toxicity. Br J Ophthalmol. 2009;93:1251-4.

44. Fraunfelder FW, Sadun AA. Update on ethambutol optic neuropathy. Expert Opin Drug Saf. 2006;5:615-8.

45. Kinoshita J, Iwata N, Maejima T, et al. Retinal function and morphology in monkeys with ethambutol-induced optic neuropathy. Invest Ophthalmol Vis Sci. 2012;53:7052-62. Histopathologic study has demonstrated retinal ganglion cells, particularly in the nasal area, are selectively damaged due to ethambutol. Demyelination and gliosis occurs in the optic nerves, chiasm, and optic tracts.

46. Boulanger Scemama E, Touitou V, Le Hoang P. Bitemporal hemianopsia as presenting sign of severe ethambutol toxicity. J Fr Ophtalmol. 2013;36:e163-7.

47. Osaquona VB, Sharpe JA, Awaji SA, et al. Optic chiasm involvement on MRI with ethambutol-induced bitemporal hemianopia. J Neuroophthalmol. 2014.

48. Danesh-Meyer HV. Radiation-induced optic neuropathy. J Clin Neurosci. 2008;15:95-100.

49. Lee MS, Borruat FX. Should patients with radiation-induced optic neuropathy receive any treatment? J Neuroophthalmol. 2011;31: 83-8. This paper gives point-counterpoint arguments for using hyperbaric oxygen in patients with visual loss due to radiation optic neuropathy.

50. Hepgül G, Tanrikulu S, Unalp HR, et al. Preventive effect of pentoxifylline on acute radiation damage via antioxidant and antiinflammatory pathways. Dig Dis Sci. 2010;55:617-25.

51. Farooq O, Lincoff NS, Saikali N, et al. Novel treatment for radiation optic neuropathy with intravenous bevacizumab. J Neuroophthalmol. 2012;32:321-4.

52. Finger PT. Anti-VEGF bevacizumab (Avastin) for radiation optic neuropathy. Am J Ophthalmol. 2007;143:335-8.

53. Hassan A, Crompton JL, Sandhu A. Traumatic chiasmal syndrome: a series of 19 patients. Clin Exp Ophthalmol. 2002;30:263-80.

54. Mohindra S, Sharma M, Monindra S. Traumatic chiasmal syndrome. Br J Neurosurg. 2012;2:872-4.

55. Heinz GW, Nunery WR, Grossman CB. Traumatic chiasmal syndrome associated with midline basilar skull fractures. Am J Ophthalmol. 1994;117:90-6.

56. Segal L, An JA, Gans M. Traumatic disruption of the optic chiasm. J Neuroophthalmol. 2009;29:308-10.

57. Atipo-Tsiba PW, Borruat FX. Traumatic dysfunction of the optic chiasm. Klin Monbl Augenheilkd. 2003;220:138-41.

58. Prasad S, Golby A. Chiasmal visual loss after retinal detachment. Neurology. 2012;78:149.

59. Dorotheo EU, Tang RA, Bahrani HM, et al. Her vision was tied down. Surv Ophthalmol. 2005;50:588-97.

60. Griffiths PG, Dayan M, Coulthard A. Primary empty sella: cause of visual failure or chance association? Eye. 1998;12:905-6.

61. Jones SE, James RA, Hall K, Kendall-Taylor P. Optic chiasmal herniation-an under recognized complication of dopamine agonist therapy for macroprolactinoma. Clin Endocrinol. 2000;53:529-34.

62. Dhanwal DK, Sharma AK. Brain and optic chiasmal herniations into sella after cabergoline therapy of giant prolactinoma. Pituitary. 2011;14:383-7.

63. Chuman H, Cornblath WT, Trobe JD, et al. Delayed visual loss following pergolide treatment of a prolactinoma. J Neuroophthalmol. 2002;22:102-6.

64. Nomikos P, Buchfelder M, Fahlbusch R. Current management of prolactinomas. J Neurooncol. 2001;54:139-50.

65. Gkekas N, Primikiris P, Georgakoulias N. Untethering of herniated left optic nerve after dopamine agonist treatment for giant prolactinoma. Acta Neurochir. 2013;155:495-6.

66. Hamlyn PJ, Baer R, Afshar F. Transsphenoidal chiasmopexy for long standing visual failure in the secondary empty sella syndrome. Br J Neurosurg. 1988;2:277-9.

67. Zona G, Testa V, Sbaffi PF, et al. Transsphenoidal treatment of empty sella by means of a silastic coil: technical note. Neurosurgery. 2002;51:1299-303.

68. Riordan-Eva P, Sanders MD, Govan GG, et al. The clinical features of Leber's hereditary optic neuropathy defined by the presence of a pathogenic mitochondrial DNA mutation. Brain. 1995;118:319-37.

69. Phillips PH, Vaphiades M, Glasier CM, et al. Chiasmal enlargement and optic nerve enhancement on magnetic resonance imaging in Leber hereditary optic neuropathy. Arch Ophthalmol. 2003;121: 577-8.

70. Ong E, Biotti D, Abouaf L, et al. Chiasmal enlargement and enhancement in Leber hereditary optic neuropathy. Neurology. 2013;81:e126-7.

71. Van Western D, Hammar B, Bynke G. Magnetic resonance findings in the pregeniculate visual pathways in Leber hereditary optic neuropathy. J Neuroophthalmol. 2011;31:48-51. This is a photo essay paper that demonstrates the subacute and chronic changes along the afferent visual pathway (from retrobulbar optic nerve to optic tracts) that can occur in patients with LHON.

72. Batioglu F, Atilla H, Eryilmaz T. Chiasmal high signal on magnetic resonance imaging in the atrophic phase of Leber hereditary optic neuropathy. J Neuroophthalmol. 2003;23:28-30. 